\title{
1-D P- and S-wave velocity models for the collision zone between the northern Tianshan mountain and the Junggar basin based on local earthquake data*
}

\author{
Anhui Sun ${ }^{1,2,3, *}$ Youshun Sun $^{4} \quad$ Haijiang Zhang ${ }^{5}$ and Diming $\mathrm{Yu}^{6}$ \\ 1 Institute of Geophysics, China Earthquake Administration, Beijing 100081, China \\ ${ }^{2}$ Institute of Earthquake Science, China Earthquake Administration, Beijing 100036, China \\ ${ }^{3}$ Key Laboratory of Earthquake Prediction, China Earthquake Administration, Beijing 100036, China \\ ${ }^{4}$ Department of Earth, Atmospheric and Planetary Sciences, Massachusetts Institute of Technology, \\ Cambridge, MA 02139-4307, USA \\ ${ }^{5}$ School of Earth and Space Sciences, University of Science and Technology of China, Hefei 230026, China \\ ${ }^{6}$ Department of Earth Science, Rice University, Houston, Texas 77005, USA
}

\begin{abstract}
We have developed crustal minimum 1-D P- and S-wave velocity models of the collision zone between the northern Tianshan mountain and the Junggar basin $\left(86^{\circ} \mathrm{E}-89^{\circ} \mathrm{E}, 43^{\circ} \mathrm{N}-44.5^{\circ} \mathrm{N}\right)$. These two models were created through inversion of $1370 \mathrm{P}$ - and $1396 \mathrm{~S}$-wave travel times from 173 well-constrained local earthquakes recorded by the Ürümqi sparse local seismic network and temporary seismic arrays. In contrast to previous models, our results indicate relatively low velocity at both shallow $(<10 \mathrm{~km})$ and deep $(30-45 \mathrm{~km})$ depths. The shallow zone is interpreted to be the result of thick surficial sedimentary deposits, whereas the deeper anomaly is interpreted to result from ductile shearing and lower crustal flow. Additionally, we detected several transition layers under the lower crust, which may imply structural complexity of the uppermost mantle in this region. The improved models reduce the RMS residual of earthquake locations by $41.7 \%$ from 1.2 to 0.5 seconds. The more accurately located hypocenters appear to correlate with prominent local over-thrusts, which underlie an anticlinal fold belt and several blind faults. Positive station corrections are observed near the Junggar basin, which likely reflects low wave velocity; negative corrections near the Tianshan mountain and Bogda mountain suggest high wave velocity.
\end{abstract}

Key words: orogenic crust; Tianshan mountain-Junggar basin; 1-D seismic structure; earthquake relocation

CLC number: P315.3 Document code: A

\section{Introduction}

The Tianshan mountain range is one of the most tectonically active intra-continental orogenic belts in the world. The boundary fault zone of the northern Tianshan piedmont delineates the collision zone between the northern part of the range and the

\footnotetext{
* Received 11 October 2012; accepted in revised form 20 November 2012; published 10 December 2012.

* Corresponding author. e-mail: sah@seis.ac.cn

(c) The Seismological Society of China, Institute of Geophysics, China Earthquake Administration, and Springer-Verlag Berlin Heidelberg 2012
}

southern edge of the Junggar basin and is characterized by valley and ridge topography (Figure 1). The Global Geosciences Transects (GGTs) indicate that the northern Tianshan mountain and the Junggar basin have similar crustal structure (Liu, 2005). The 1965 M6.6 Bogda earthquake and the 1906 M7.7 Manas earthquake (solid red stars, Figure 1) are the largest recorded earthquakes in the Tianshan orogenic belt, and occurred within the collision zone. Active deformation has continued through the Holocene in response to the IndianEurasian collision, which may began 55 million years ago (Tapponnier et al., 2001), and as a result of regional subduction of the Tarim sub-plate and orogeny (Xiao 
et al., 1990). Deformation of the northern piedmont of the Tianshan is manifested by three sub-parallel sets of reverse faults and fold belts that are developed in the Cenozoic strata within the Ürümqi depression (Wang et al., 2004; Qi et al., 2008). This special tectonic structure, consisting of shovel-shaped faults zones and gentle decollement slopes, is widely distributed in the study area (Deng et al., 1999), and has the potential to accumulate strain energy. A quick release of the accumulated energy then reaches the surface to generate large-scale destruction (e.g., $M_{\mathrm{S}} 8.0$ Wenchuan earthquake; Tao et al., 2011).

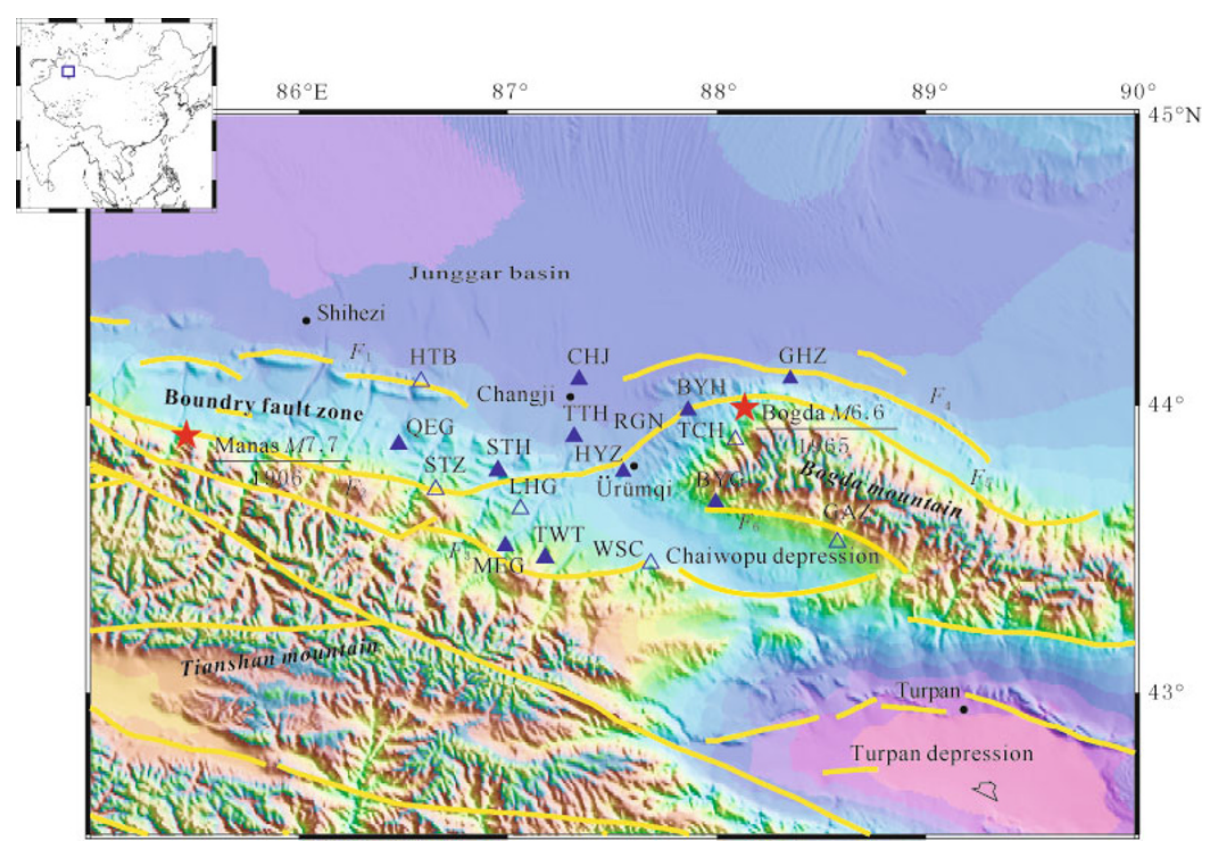

Figure 1 Tectonic map of the study region in Northwest China showing the location of seismic stations. The hollow blue triangles indicate the locations of the stations from the local seismic network and the solid blue triangles from the temporary array. Yellow lines delineate fault surface traces. $F_{1}$. Manas-Tugulu anticline; $F_{2}$. Qigu-Tuositai anticline; $F_{3}$. Tianshan northern piedmont fault; $F_{4}$. Fukan-Santai fault; $F_{5}$. Bogda northern piedmont fault; $F_{6}$. Bogda southern piedmont fault.

Investigations of the seismotectonic structure of the crust require high quality databases including reliable 1-D reference velocity models and accurate earthquake locations. Unfortunately, research of the study area has typically been focused on field-based geologic studies, and 3-D crustal structure tomography (Xu et al., 2000b; Qian et al., 2011) is of fairly low resolution due to technological limitations and limited data. Moreover, the obtained solutions and the reliability estimates depend on the initial 1-D reference model (Kissling et al., 1994). Several previous 1-D models referring to a single 2-D profile of deep seismic sounding (DSS) (Shao et al., 1996; Wang et al., 2004) cannot satisfy the whole target area, nor is the global crustal model CRUST 2.0 (Bassin et al., 2000) suitable for investigations of local seismology in this study, because the dataset is too sparsely sampled.

In this paper, we make use of recently obtained data from the established local seismic network and temporary seismic arrays to develop an overall average $1-\mathrm{D}$ velocity model for the crust and uppermost mantle of the Tianshan-Junggar collision zone. Inversion of Pand S-wave travel times is performed using the program VELEST (Kissling et al., 1994) to obtain the "minimum 1-D velocity model". In addition, we relocated earthquake events that occurred from 1988 to August 2005 by using our newly updated 1-D reference model, which greatly reduced the RMS residual of their locations. Because high precision seismicity can be used to detect crustal shear zones (Shearer, 2002) and to identify hidden active faults (Courboulex et al., 2003), we used the structures obtained by deep seismic reflection profile experiments (Liu et al., 2007) and our accurate relocation of hypocenters to delineate faults zones. These results illuminate the possible deep crustal geodynamic evolution of this seismotectonic block. 


\section{Data and methods}

We deployed 10 broadband temporary seismic stations in the Tianshan-Junggar collision zone from July 2004 to August 2005, which was supported by the Ürümqi Active Faults Detection Project. The observation system consisted of a Guralp CMG-3ESP seismometer and a REF TEK 130 digitizer with a sampling rate of $50 \mathrm{sps}$, with a GPS working in continuous mode. The temporary stations, combined with the 17 seismic stations of the Ürümqi network, yielded a higher density seismic network with a station spacing of 20-40 km in the target area (Figure 1). We have hand-picked arrival times from the waveforms recorded by our temporary stations for more than one year. In addition, we have selected events from the Xinjiang monthly catalog and collected a total of $6665 \mathrm{P}$ - and $6371 \mathrm{~S}$-wave travel times to jointly invert for hypocenters and a layered crustal model.

For a 1-D model inversion, we measured the total travel time misfit (or residuals) often by using the RMS (root-mean-squared) misfit of the solution, and the target for most inversions is to address a global minimum for this RMS misfit. In the case of the coupled hypocenter-velocity problem, however, the solution depends on the initial model and initial hypocenter parameter, thereby most likely yielding several local minima, but not a global minimum. Calculating the 1-D minimum model avoids this situation through varying initial models and hypocenters performed by the program VELEST. The 1-D minimum models including a 1-D model and the station corrections are the result of a combined, simultaneous inversion of a large number of selected high-quality earthquakes. The attributed "minimum" denotes the fact that this 1-D model and the station corrections lead to a minimum average (RMS) value for all events used in the inversion.

To develop a reasonable reference model with evenly distributed recorded data, we only used data from earthquakes that occurred from July 2004 to August 2005, such that the temporary station data could have equal weight to the seismic network data in the inversion process. Following the VELEST protocol, we prepared three different earthquake event groups. One group contains 501 events from the Xinjiang monthly routine catalog (C65), with more than four-station recordings for each event. The other groups consist of 727 relocated results of adopted earthquakes determined with Hypoinverse (Klein, 2002), and 417 relocated earthquakes determined through application of hypoDD (Waldhauser and Ellsworth, 2000), respectively. To further reduce the systematic errors in the dataset, and to further improve the stability of inversion, we chose events according to the following criteria: from a minimum number of six stations, with $2.3 \leq v_{\mathrm{P}} \leq 8 \mathrm{~km} / \mathrm{s}$, between the estimated minimum value of $\mathrm{P}$-wave velocity near surface and the $\mathrm{P}$-wave velocity near uppermost mantle around the study area from previous research (Xiao et al., 2004), and GAP $\leq 180$. GAP refers to the largest azimuthal gap (degrees) between azimuthally adjacent stations. Then, we selected 321 earthquakes from the Hypoinverse relocated results, and 173 earthquakes from the hypoDD relocated results as two additional event groups for inversion.

We utilized three 1-D prior models with $v_{\mathrm{P}} / v_{\mathrm{S}}$ ratio of 1.73 from previous studies (Shao et al., 1996; Wang et al., 2004; Sun et al., 2011) as our initial 1-D velocity models (dashed lines in Figures 2a-2b), in which we (Sun et al., 2011) revised the velocity of very shallow depth according to the DSS result (Xiao et al., 2004), and verified that the shallow part of the 1-D model is important for location. Kissling et al. (1994) pointed out that the coupled hypocenter-velocity inversion solution obtained by any iterative algorithm strongly depends on the initial model and initial hypocenter locations. As described above, we assigned three groups of earthquake events and selected three initial models, from which we obtained nine combinations of event groups and initial models by pairwise bonding. For each combination, we first applied VELEST algorithms to obtain its 1-D velocity models with minimal misfit (RMS residual), so that each event groups can create three VELEST output models based on three different initial models. After comparing the RMS residuals of these three event groups, we selected one event group with the smallest RMS residual on the whole, and then merged its three output models by taking an average to obtain a new 1-D model, named VM1. Because VELEST does not automatically adjust the thickness of model layers, we linearly interpolated several layers for three initial models by following the approach of Kissling et al. (1994), where we put the trial layer thickness at $2 \mathrm{~km}$ for shallow crustal levels and increased layer thickness with increasing depth to approximately 4 to $5 \mathrm{~km}$ near Moho depths. Following the same derivation process for the model VM1, we created the VM2 model from these three new modified initial models with three event groups. Finally, with the two newly created models VM1 

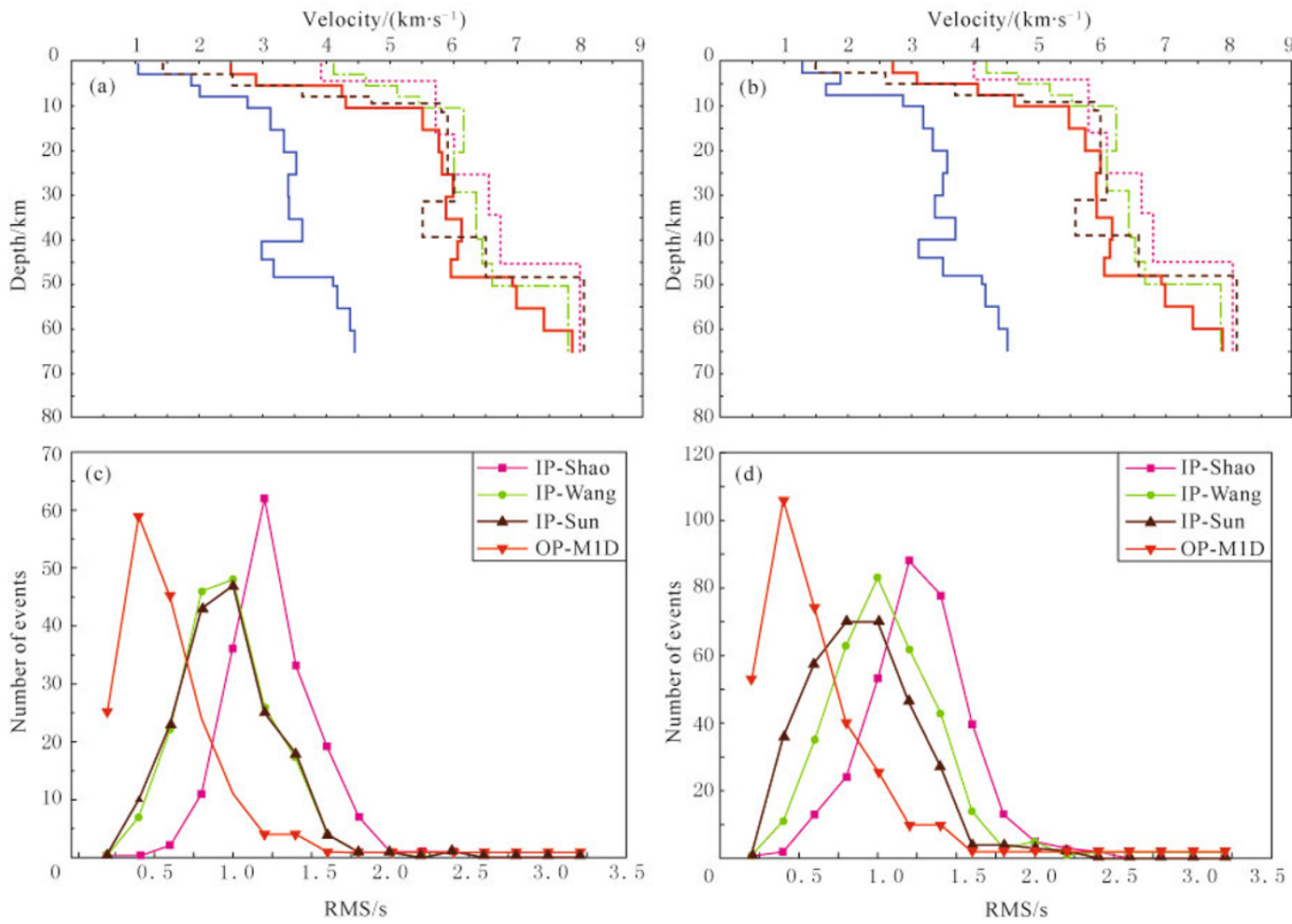

Figure 2 Three initial models and estimated 1-D velocity models for two event groups by hypoDD (a) and Hypoinverse (b), and the corresponding difference between the RMS residuals of hypocenters located by them (c, d). For (a) and (b), the solid red line shows the improved 1-D P velocity model, the solid blue line shows the improved 1-D S velocity model, the pink line shows the initial model from Shao et al. (1996), the green line shows the initial model from Wang et al. (2004), and the brown line shows the initial model from Sun et al. (2011). For (c) and (d), "IP" means input model and "OP" means output model.

and VM2, we re-ran VELEST for three event groups. The inversion iteration stopped when earthquake location and velocity of model layers became stable. The output models with close minimum RMS residuals based on the models VM1 and VM2 are similar (solid lines in Figures $2 \mathrm{a}-2 \mathrm{~b}$ ), indicating that our inversion is stable and reliable.

\section{Results}

Due to the fact that some events in the C65 event group are the outliers with large location errors, the resulting output RMS residuals of the group are significantly larger than those of the other two event groups (Table 1), which indicates the need to improve the quality of earthquake locations through preliminary relocation. In the following we will discuss the computation only for hypoDD and Hypoinverse event groups. We preferred to choose the model iterated from VM1 and the hypoDD event group as our minimum 1-D velocity model because of smaller RMS values for the three event groups (solid red lines, Figure 2a). Consequently, we can achieve the smallest RMS residuals of earthquake locations. Finally, our dataset contained $1370 \mathrm{P}$ - and 1396 S-waves, including 1473 direct waves and 1293 refracted waves, which covers the crustal depth range well. As compared to the three initial models, our estimated 1-D velocity model shows a reduction of total RMS values of all events for either event groups (Figures $2 \mathrm{c}, 2 \mathrm{~d}$ ), and can thus be used to relocate earthquakes more accurately.

Table 1 The calculated RMS residual of hypocenters after inversion for different initial date combination

\begin{tabular}{cll}
\hline \multirow{2}{*}{ Events group } & \multicolumn{2}{c}{ RMS residual } \\
\cline { 2 - 3 } & VM1 & VM2 \\
\hline C65 & 2.02 & 2.1 \\
hypoDD & 0.53 & 0.54 \\
Hypoinverse & 0.58 & 0.59 \\
\hline
\end{tabular}


In constructing the minimum 1-D velocity model, two sets of station corrections were iteratively inverted along $i$-th layer velocities by VELEST with positive and negative values corresponding to relatively slow (later arrivals) and fast (early arrivals) wave velocities, respectively. These corrections reveal discrepancies between the 1-D minimum velocity model and the true velocity structure below stations, and can reduce the effect of crustal inhomogeneity. The obtained station corrections were considered to be related to subsurface geology and the depth of the Moho, but not to elevation. Our results suggest that most stations at the Junggar basin are located in a local slow velocity area, and that most stations near the northern Tianshan mountain are located in a local high velocity area with respect to the reference station LHG (white solid circle, Figure 3a).

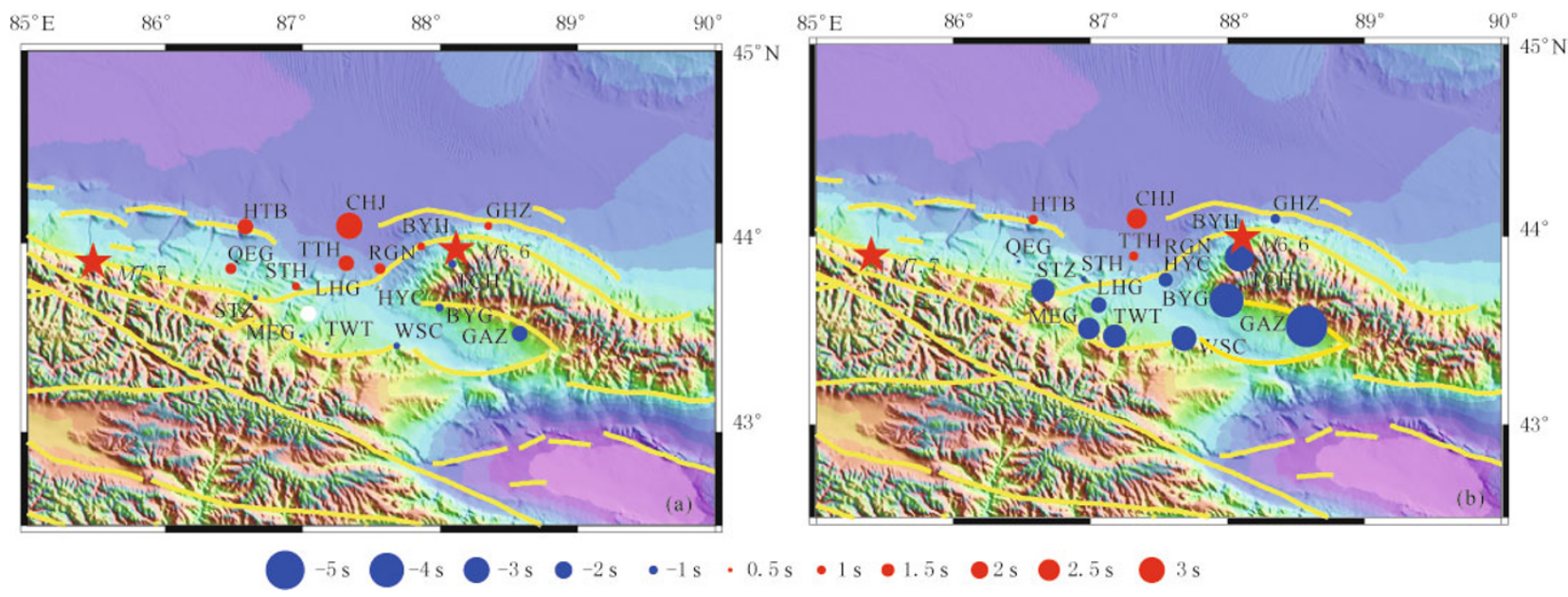

Figure 3 P-wave (a) and S-wave (b) station corrections obtained in this study. Solid circles indicate station corrections with size proportional to magnitude. Red stars denote 1965 M6.6 Bogda and 1906 M7.7 Manas earthquakes.

The Tianshan mountain northern piedmont fault continuously extend northward, through a deep blindthrust fault slope, to a complex multi-level decollement of thrust faults that developed in Cenozoic strata. The depth of the main decollement is $8-9 \mathrm{~km}$, and the upper decollement is $3-4 \mathrm{~km}$ (Deng et al., 1999). For our $1-\mathrm{D}$ minimum velocity model, the average $\mathrm{P}$-wave velocity in the shallow upper crust $(<10 \mathrm{~km})$ is $3.57 \mathrm{~km} / \mathrm{s}$, which is also consistent with the thick section of sedimentary strata within the Ürümqi depression (Liu et al., 2007). In contrast to previous 1-D models (Shao et al., 1996; Wang et al., 2004; Sun et al., 2011), our work has revealed relatively low velocity zones at two different depth ranges. The upper zone, at $\sim 30 \mathrm{~km}$ depth, is a possible ductile shear zone between the upper and lower crusts, which has distinct physical properties. This putative shear zone is interpreted to be a zone of detachment faulting beneath thin-skinned folding and faulting that resulted from compressional stress (Xu et al., 2000a). The second low velocity zone is at a depth of $\sim 45 \mathrm{~km}$ and is marked by especially low S-wave velocity (solid blue lines, Figures 2a, 2b), which were evident in 3-D imaging (Wang et al., 2008). This may be the result of a zone of partial melting at the bottom of the lower crust, potentially influenced by small-scale convective flow from the uppermost mantle (Xu et al., 1998). This interpretation is in contrast to that of Zhao et al. (2004), in which lower crust material beneath the Junggar basin is thought to have been brought to the uppermost mantle of Tianshan orogenic belt during the north to south subduction of the Junggar tectonic block under the Tianshan orogenic belt.

There are several different depths reported as the location of the Moho discontinuity around the study area, including about $50 \mathrm{~km}$ depth from gravity research (Zhang et al., 2011), and $60 \mathrm{~km}$ depth from deep sounding profiles (Xiao et al., 2004). We detected several slightly increased velocity layers at depths greater than $48 \mathrm{~km}$, similar to what has been seen in the Tianshan mountain of Kyrgyzstan (Xu et al., 2000b). Deep seismic sounding and seismic tomographic profiles across the Tianshan orogenic belt similarly indicated that gradual velocity changes occur in the crust-mantle transition zone with layer thickness of approximately 10 to $20 \mathrm{~km}$ (Shao et al., 1996; Zhao et al., 2001; Liu et al., 2007). Since nearly half of our dataset were refracted rays, our obtained models could reveal complexities of the crust-mantle transition zone. However, im- 
proved resolution could be obtained if we conducted 3-D tomography by introducing more crossed rays of distant earthquakes based on our average 1-D structure.

Finally, we determined 781 earthquake hypocenters by applying the method hypoDD to relocate 2370 earthquakes that occurred from 1988 to 2005 on the newly obtained 1-D crustal P-wave velocity model. The average depth of the hypocenters is $16.8 \mathrm{~km}$ with $75.8 \%$ being located between $5 \mathrm{~km}$ and $25 \mathrm{~km}$ depth. We reduce the average horizontal error ellipse calculated by LSQR (Paige and Saunders, 1982) from $664.6 \mathrm{~m}$ to 125.6 $\mathrm{m}$ in the east-west direction, $664.6 \mathrm{~m}$ to $149.3 \mathrm{~m}$ in the north-south direction, and errors in depth are reduced from $669.7 \mathrm{~m}$ to $155.7 \mathrm{~m}$. When the same method and parameters were used with the model of Shao et al. (1996), the horizontal error ellipse was reduced to $191.3 \mathrm{~m}$ in EW, $210.4 \mathrm{~m}$ in NS, and the depth error to $274.5 \mathrm{~m}$. Thus, our minimum 1-D velocity model further improves earthquake location precision.

In plan view (Figure 4a), the Tianshan northern piedmont fault $\left(F_{3}\right)$, the dividing line between the Jung-

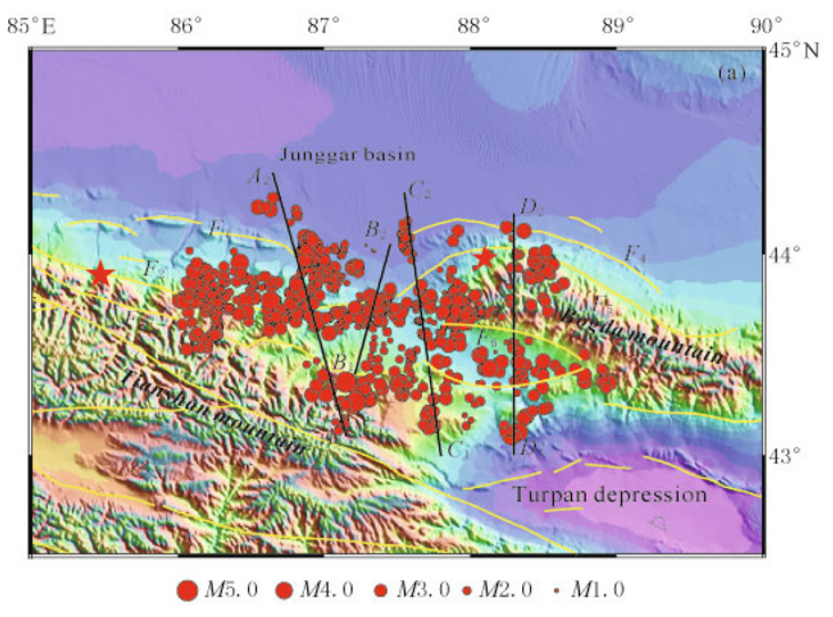

gar tectonic block and the active continental margin of North Tianshan (Deng et al., 1999), is a thrust deep fault. The orogenic process of collision between the Indian plate and the Eurasian plate caused the Tianshan mountain and the Bogda mountain to uplift abruptly (Tapponnier et al., 2001), and the thrust TianshanJunggar transition zone is generally deflected in the regional compression strain environment. The relocation results show that the earthquake events selected are mainly distributed around the Tianshan-Junggar deflection belt area, dominantly consisting of the fault $F_{3}$, and clustering at some thrust faults and anticline area. For example, the Hutubi anticline, a latest active anticline located at northeast of Tugulu anticline, is suggested as the result of the Manas reverse fault expanding eastward and grows a minor uplift at surface (Deng et al., 1999). The selected events are also distinctly aligned south of the surface trace of the Manas-Tugulu anticline and fold deflection belts of the Bogda northern piedmont, where there are several parallel anticlines and thrust faults.

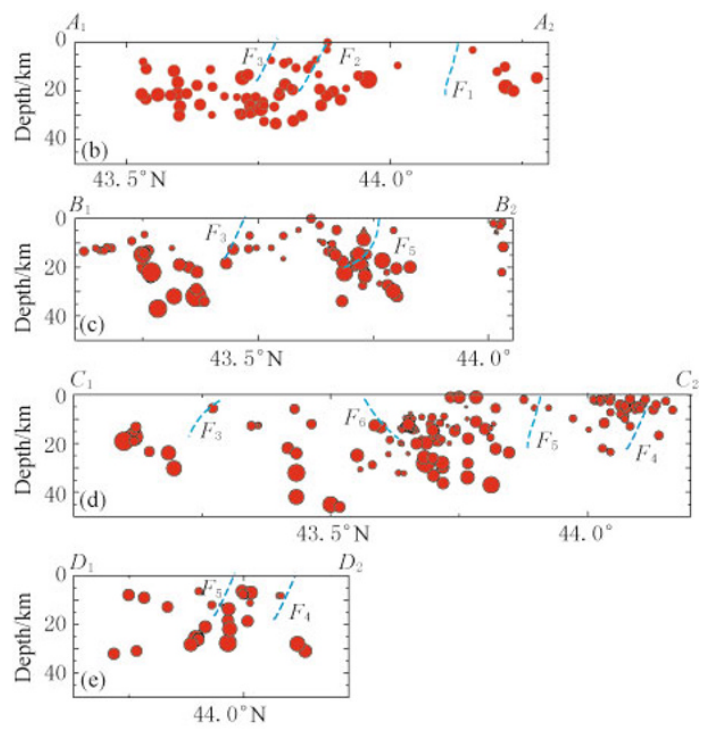

Figure 4 Distribution of relocated earthquakes within $10 \mathrm{~km}$ on both sides of the four profiles $A_{1} A_{2}, B_{1} B_{2}, C_{1} C_{2}$, and $\left.D_{1} D_{2}\right)$ (a) and plan views of the four profiles (b-e) where the faults $F_{1}-F_{6}$ (blue dashed lines) refer to deep seismic reflection profiles (Liu et al., 1994; Liu et al., 2007; Qi et al., 2008), and their meanings are the same as those in Figure 1.

In the profiles of Figures $4 \mathrm{~b}-4 \mathrm{e}\left(A_{1} A_{2}, B_{1} B_{2}\right.$, $\left.C_{1} C_{2}, D_{1} D_{2}\right)$, we find that most earthquakes are distributed at a depth range above $30 \mathrm{~km}$, reflecting the widespread thrustnappe character, and event distributions in closely proximity to the mountains dip more steeply, appearing to follow the bounding reverse fault that separates the rigid hanging wall of Tianshan moun- tain block from the Junggar basin block. At the boundary area, this may indicate that the deep blind faults ruptured downward when they collided with the rigid tectonic block in the folding process. The rigid upper crust of the Tianshan could have detached along the ductile shear zone in the mid-crust, contemporaneously with horizontal N-S compression and deformation forces 
due to the hot material upwelling from the upper mantle. Xu et al. (2005) suggested that uneven compression may have caused a decollement to develop at the bottom of the crust, and that the Tianshan block penetrated to the southern edge of the rigid Junggar basin block along faults in the deep crust at the collision boundary. This action led to the deformation of the lithosphere between the orogenic belt and adjacent basin.

Referring to the geometrical character of several of the faults and anticlines in profiles (Liu et al., 1994; Liu et al., 2007; Qi et al., 2008), earthquakes mostly occur in the hanging wall of these thrust faults, as shown in Figure 4b. In Figure 4c, the earthquakes occurred below the depression area between $F_{3}$ and $F_{5}$ dip more gently than those below mountainous area. These findings are consistent with the presence of a detachment found in deep seismic reflection profiles of Liu et al. (2007). The Chaiwopu depression, located between the Tianshan mountain and the Bogda mountain, is common footwall of Tianshan northern piedmont fault $\left(F_{3}\right)$ and Bogda southern piedmont fault $\left(F_{6}\right)$ (Qi et al., 2008). The profile $C_{1} C_{2}$ (Figure $4 \mathrm{~d}$ ) crosses over the Chaiwopu depression and the Bogda mountain from south to north, in which most events occurred between $F_{5}$ and $F_{6}$, where the collision area of the Bogda mountain and Ürümqi depression was found. Some events between $F_{3}$ and $F_{6}$ are located deeper than $40 \mathrm{~km}$ depth below the Chaiwopu depression, similar to those below the central Tianshan mountain (Xu et al., 2005). Considering the universal knowledge about viscosity of middle-bottom crust, we re-audited these original hypocenter parameters, in which the depths are beyond $40 \mathrm{~km}$ as well. We need to further confirm it in depth by using reflection phases like $\mathrm{pP}$ and $\mathrm{PmP}$ of waveforms recorded by seismic stations in the future. In the northward thrusting and extension orogenic process of the Tianshan mountain, the tectonic activity of the deflection belt between Bogda northern piedmont fault $\left(F_{5}\right)$ and Fukan-Santai fault $\left(F_{4}\right)$ is complicated, which formed some smallscale thrust fault zones and fold structures. We find that many earthquakes occurred below deflection belt area in the profile $D_{1} D_{2}$ (Figure 4e). Furthermore, most events relocated with relatively larger magnitude are dominantly distributed at deeper depths than smaller ones, implying that the stress is not easy to accumulate in shallow depression regions to create a large earthquake. Qi et al. (2008) pointed out that the shallow tectonic deformation at the Tianshan-Junggar area was mainly controlled by the relatively weak strata of the Jurassic and Paleogene.

\section{Discussion and conclusions}

Our newly relocated hypocenters may aid in the discovery of blind and deep fault zones, delineating the boundaries of sub-plates (Figures 4b-4e), which is of potential use in oil and gas exploration. However, the 1-D crustal reference velocity model does not provide a full representation of the structural complexity of the study area; even the hypoDD method cannot eliminate uncertainties associated with the model. To further improve relocation precision, future work should focus on arrival time picking, seismic station coverage, and relocation using a 3-D model. In additional, the focal mechanism solutions of regional earthquakes also help to verify the distribution and features of the fault.

By inverting $\mathrm{P}$ - and S-wave travel times recorded by the local seismic network and a temporary seismic array, we have developed average 1-D P-wave and Swave velocity crustal models for the collision zone between the northern Tianshan mountain and the Junggar basin. We then relocated the events that occurred in the previous decades with this new improved reference model. Our models have improved the accuracy of hypocenter determination by significantly reducing RMS residuals of earthquakes and locating errors. In accordance with previous studies of regional geological structure, the distribution of relocated earthquakes may reveal the coherence with the distinct local over-thrust anticline belt.

Acknowledgements The China Earthquake Networks Center (CENC) provided earthquake data for this research, and we are grateful for help in field work and data processing from the following people: Dr. Haitao Wang, Dr. Zhihai Li of Earthquake Administration of Xinjiang Uygur Autonomous Region, Mr. Gang Li of CENC, and Mr. Zhiqiang Zhang of the Institute of Earthquake Science, China Earthquake Administration (CEA). We thanks for the thoughtful advices from Dr. Xiangfang Zeng of University of Science and Technology of China and Dr. Shunping Pei of Institute of Tibetan Plateau Research, Chinese Academy of Sciences. The comments from the anonymous reviewers have been constructive in improving our manuscript. We plotted most figures using GMT (Wessel and Smith, 1995). The research was supported by Basic Research Project of Institute of Earthquake Science, CEA (grant No. 2012IES010103) and National Natural Science Foundation of China (grant No. 41204037). 


\section{References}

Bassin C, Laske G and Masters G (2000). The current limits of resolution for surface wave tomography in North America. EOS Trans AGU 81: F897.

Courboulex F, Larroque C, Deschamps A, Gélis C, Charreau J and Stéphan J F (2003). An unknown active fault revealed by microseismicity in the south-east of France. Geophys Res Lett 30(15): 1 782-1 785.

Deng Q D, Feng X Y, Zhang P Z, Yang X P, Xu X W, Peng S Z and Li J (1999). Reverse fault and fold zone in the Ürümqi range-front depression of the northern Tianshan and its genetic mechanism. Earth Science Frontiers 6(4): 191-201 (in Chinese with English abstract).

Kissling E, Ellsworth W L, Eberhart-Phillips D and Kradolfer U (1994). Initial reference models in local earthquake tomography. J Geophys Res 99(B10): $19635-19646$.

Klein F W (2002). User's Guide to Hypoinverse-2000: A Fortran Program to Solve for Earthquake Locations and Magnitudes. USGS Open File Report, 02-171.

Liu B J, Shen J, Zhang X K, Chen Y, Fang S M, Song H P, Feng S Y and Zhao C B (2007). Crust structures and tectonics of Ürümqi depression revealed by deep seismic reflection profile in the northern margin of Tianshan mountains. Chinese J Geophys 50(5): 1 464-1 472 (in Chinese with English abstract).

Liu H F, Liang H S, Cai L G, Xia Y P and Liu L Q (1994). Evolution and structural style of Tianshan and adjacent basins, northwestern China. Earth Science-Journal of China University of Geosciences 19(6): 727-741 (in Chinese with English abstract).

Liu X (2005). A study of the crustal tectonic evolution in basin-mountain areas of Northwest China in the light of Xinjiang geotransect. Acta Geoscientia Sinica 26(2): 105-112 (in Chinese with English abstract).

Paige C C and Saunders M A (1982). LSQR: An algorithm for sparse linear equations and sparse least squares. $A C M$ Transactions on Mathematical Software (TOMS) 8(1): $43-71$.

Qi J F, Chen S P, Yang Q and Yu F S (2008). Characteristics of tectonic deformation within transitional belt between the Junggar Basin and the northern Tianshan Mountain. Oil \& Gas Geology 29(2): 252-260 (in Chinese with English abstract).

Qian H, Jiang M, Xiao W J, Zhao D P, Wang Y, Zhang L S and Zhao L (2011). Seismic tomography of TianshanJunggar region and its lithospheric structure. Acta Seismologica Sinica 33(3): 327-341 (in Chinese with English abstract).

Shao X Z, Zhang J R, Fan H J, Zheng J D, Xu Y, Zhang H Q, Pomanhov U and Tarasenko U (1996). The crust structures of Tianshan orogenic belt: a deep sounding work by converted waves of earthquakes along Ürümqi-Korla profile. Chinese J Geophys 39(3): 336-346 (in Chinese with English abstract).

Shearer P M (2002). Parallel fault strands at 9-km depth resolved on the Imperial Fault, Southern California. Geophys Res Lett 29(14): 1 674-1 677.

Sun A H, Chen Q F, Chen Y, Li G and Zhang Z Q (2011). Relocation of earthquakes in the northeastern Tianshan Mountains area and improvement of local 1-dimensional crustal velocity model. Earthquake Research in China 27(3): 235-247 (in Chinese with English abstract).

Tao W, Hu C B, Wan Y G, Shen Z K and Wang K (2011). Dynamic modeling of thrust earthquake on listric fault and its inference to study of Wenchuan earthquake. Chinese J Geophys 54(5): 1 260-1 269 (in Chinese with English abstract).

Tapponnier P, Xu Z Q, Roger F, Meyer B, Arnaud N, Wittlinger G and Yang J S (2001). Oblique stepwise rise and growth of the Tibet Plateau. Science 294(5547): 1 6711677 .

Waldhauser F and Ellsworth W L (2000). A doubledifference earthquake location algorithm: method and application to the northern Hayward fault, California. Bull Seismol Soc Am 90(6): 1 353-1 368.

Wang C Y, Yang Z E, Luo H and Mooney W D (2004). Crustal structure of the northern margin of the eastern Tien Shan, China, and its tectonic implications for the 1906 M7.7 Manas earthquake. Earth Planet Sci Lett 223(1-2): 187-202.

Wang Z H, Liu J, Zhou L Q and Wang H T (2008). Tomography of 3-D velocity in Earth's crust and upper mantle of middle Tianshan. Inland Earthquake 22(3): 203-211 (in Chinese with English abstract).

Wessel P and Smith W H F (1995). New version of the Generic Mapping Tools released. EOS Trans AGU 76(33): 329.

Xiao X C, Liu X and Gao R (2004). The Geoscience Transect for Tianshan Mountains-Tarim-Kunlun Mountains in China. Geological Publishing House, Beijing, 27-37 (in Chinese).

Xiao X C, Tang Y Q, Li J Y, Zhao M, Feng Y M and Zhu B Q (1990). On the tectonic evolution of the northern Xinjiang, Northwest China. Geoscience of Xinjiang 1: 47-68 (in Chinese with English abstract).

Xu Y, Liu F T and Liu J H (1998). Upper mantle structure in the Tianshan and its geodynamic role to crustal tectonic movement. Seismology and Geology 20(4): 405-412 (in Chinese with English abstract).

Xu Y, Liu F T, Liu J H and Sun R M (2000a). Crustal structure and tectonic environment of strong earthquakes in the Tianshan earthquake belt. Chinese J Geophys 43(2): 184-193 (in Chinese with English abstract).

Xu Y, Liu F T, Liu J H, Sun R M and He J K (2000b). Seismic tomography beneath the orogenic belts and adjacent basins of northwestern China. Science in China (Series D) 30(2): 113-122 (in Chinese with English abstract). 
Xu Y, Steven W R, Wei R P, Zhang W L and Wei B (2005). Analysis of seismic activity in the crust from earthquake relocation in the Central Tianshan. Chinese $J$ Geophys 48(6): 1 308-1 315 (in Chinese with English abstract).

Zhang Z J, Yang L Q, Teng J W and Badal J (2011). An overview of the earth crust under China. Earth-Science Reviews 104(1-3): 143-166.

Zhao J M, Liu G D, Lu Z X, Zhang X K and Zhao G Z
(2001). Crust-mantle transitional zone of Tianshan orogenic belt and Junggar Basin and its geodynamic implication. Science in China (Series D) 44(9): 824-837.

Zhao J M, Li Z C, Cheng H G, Yao C L and Li Y S (2004). Structure of lithospheric density and geomagnetism beneath the Tianshan orogenic belt and their geodynamic implications. Chinese J Geophys 47(6): 1 061-1 067 (in Chinese with English abstract). 